\title{
Study of Stiffness of Linear Guide Pairs by Experiment and FEA
}

\author{
Azhar Shaukharova, Yi Liang, Hutian Feng, Bin Xu \\ Department of Mechanical Engineering, Nanjing University of Science and Technology, Nanjing, China \\ Email: 2650073457@qq.com
}

How to cite this paper: Shaukharova, A., Liang, Y., Feng, H.T. and Xu, B. (2016) Study of Stiffness of Linear Guide Pairs by Experiment and FEA. World Journal of Engineering and Technology, 4, 115-128. http://dx.doi.org/10.4236/wjet.2016.43D015

Received: September 2, 2016 Accepted: October 13, 2016

Published: October 20, 2016

\begin{abstract}
Linear guide pairs are the main part of the CNC machine tools. The dynamic behaviours are the main properties of the linear guide. These properties can mainly increase the service life of linear guide pairs. The main propose of this study is the comparison of stiffness of linear guide pairs by FEA and experiment. Measure the stiffness experimentally and, compare the results with FEA to prove the correctness of FEA model. For studying was chosen three linear guides: Chinese company-1, Chinese company- 2 and abroad company. The results of this study are (1) Set up the finite element model of linear guides with different geometrical parameters. (2) Comparison of FEA and experiment results shows almost same results. (3) The FEA results show correctness of analysis. These studies are useful for establishing the stiffness on different structures of linear guides.
\end{abstract}

\section{Keywords}

Linear Guide Pair, Vibration, Stiffness, FEA

\section{Introduction}

Rolling element linear motion bearings are widely used to guide, support, locate, and accurately move machinery components and products in a wide range of automation applications. Rolling element linear bearings and guides provide low friction, smooth, accurate motion for nearly any moment or normal loading condition. Major applications include factory automation, medical, packaging, machine tool, semiconductor, printing, automotive assembly, aerospace and food processing [1].

Geometrical differences of linear guides effect on properties. The structure and geometrical parameters have differences. LM guides supported by non-contact bearings require complex and expensive fabrication process [2]. LM guides using ball bearings have advantages such as high stiffness, relatively good reliability, and low cost [3]. Ac- 
cording to the study Lay and Hung [4], the bearing stiffness of the rolling elements is determined by the preloaded state of the rolling balls and has been shown to have significant influences on the dynamic characteristics of the stage [5] [6]. Harsha [7] studied the bearing stiffness might increase with an increase in the number of the balls in a ball bearing, which further stiffness of bearing is increased and vibration amplitude of the shaft is reduced. Lynagh [8] proved that the bearing stiffness of angular contact bearings decreases with increase in rotational speed, which consequently affects the spindle dynamics. A. Dadalau analyzed by finite element analysis and theoretically the relationship between contact force and stiffness [9] [10].

James Shih-Shyn Wu studied contact stiffness and dynamic characteristics of linear guide under moment load by finite element method and experimentally [11]. Lei Li used finite element method to determine the stiffness and damping by measuring the frequency. Analysis of the dynamic characteristics of linear guide used the modal analysis method based on the finite element method. The accurate experimental results by Hertz theory and identification method of frequency domain are determined [12]. D. Shaw and W. L. Su researched the stiffness of numerical analysis results and experimental results of a linear guide pairs were obtained. The comparison shows that the numerical model is reasonable correct [13]. Creation of the finite element models for all structure components is a complicated task, especially when the variation in dynamic characteristics with the change in configuration of the structure modules is concerned [14]-[18]. The research of D. Shaw and W. L. Su show that lower ball of 2 rows were separated without point contact. In this paper will try show that the upper 2 row ball has more deformation than down row ball. And lower ball of 2 rows will not separate without point contact. Till this time, many researchers studied the properties of linear guide pairs. In this paper will consider the effect of stiffness on different structural linear guide pairs under one load. Experiment is done and the results will compare in below of paper. Further, experiment results are compared.

\section{Finite Element Analysis}

\subsection{Description of Structures Selected Linear Guide Pairs}

Three linear guide pairs are chosen for studying. They are abroad company, Chinese company- 1 and Chinese company-2. The differences between them are in geometrical parameters.

Linear guide pair application is the same. These types of linear guides are the most widely used guide pairs. Contact angle designed with equal $45^{\circ}$ (Figure 1), which makes



Figure 1. Schematic illustration of $45^{\circ}$ angular contacts [18]. 
equal load in four directions-vertical upside, vertical downside, horizontal left and right. It transports an LM block by use of four rows of recirculating balls.

\subsection{D Models Preparing for Finite Element Analysis of Stiffness}

The procedures of the finite element analysis are as shown in Figure 2.

Figure $\mathbf{2}$ is the flowchart of steps of process of finite element analysis. If analysis has differences with experiment data, the boundary condition will set up till good results.

\section{Pre-process performed:}

CAD model is set up according the parameters as in company's handbook. The FE model consist of three parts, to get the accurately results respectively to experiment data. The model is set up in Proengineer. The geometric parameters for linear guides are shown in Figure 3 and Table 1.

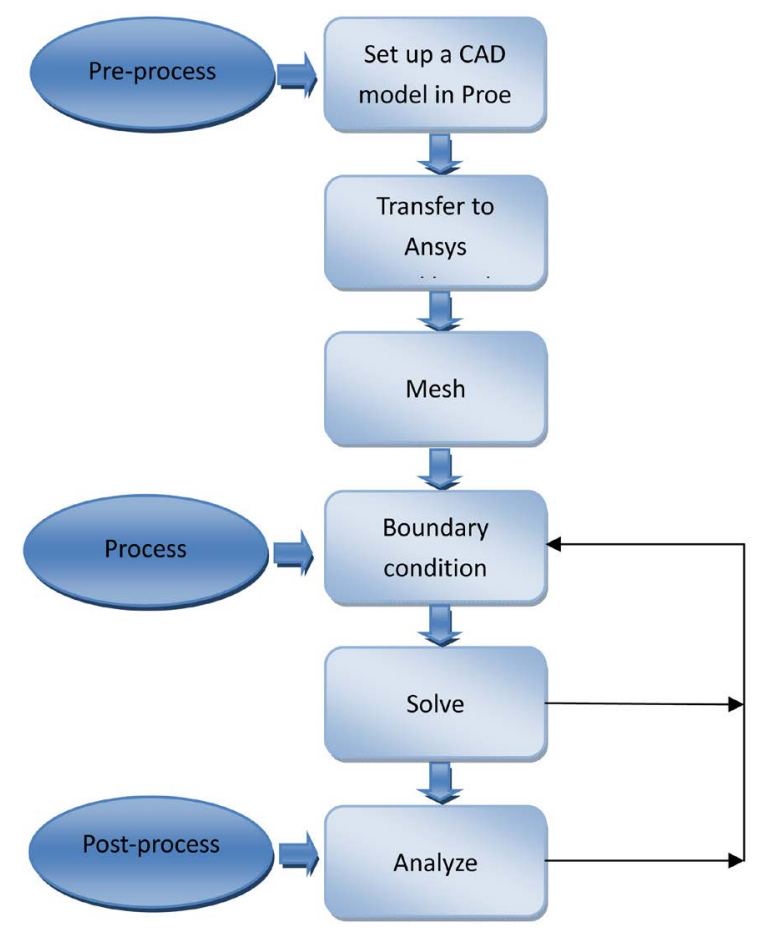

Figure 2. The flowchart of FEA process.

Table 1. Parameters of linear guide.

\begin{tabular}{cccc}
\hline Parameters & Abroad company & Chinese company-1 & Chinese company-2 \\
\hline $\mathrm{D} \mathrm{a} / \mathrm{mm}$ & 6.54 & 6.54 & 6.54 \\
$\varphi_{1} /^{\circ}$ & $45^{\circ}$ & $45^{\circ}$ & $45^{\circ}$ \\
$\mathrm{H}_{1} / \mathrm{mm}$ & 32 & 38 & 38 \\
$\mathrm{H} / \mathrm{mm}$ & 60 & 70 & 70 \\
$\mathrm{~K} / \mathrm{mm}$ & 44.6 & 59 & 60.5 \\
$\mathrm{~B}_{4} / \mathrm{mm}$ & 43.717 & 45 & 45 \\
$\mathrm{~B}_{1} / \mathrm{mm}$ & 80.6 & 86 & 86 \\
$\mathrm{~L} / \mathrm{mm}$ & 106 & 105 & 103 \\
\hline
\end{tabular}




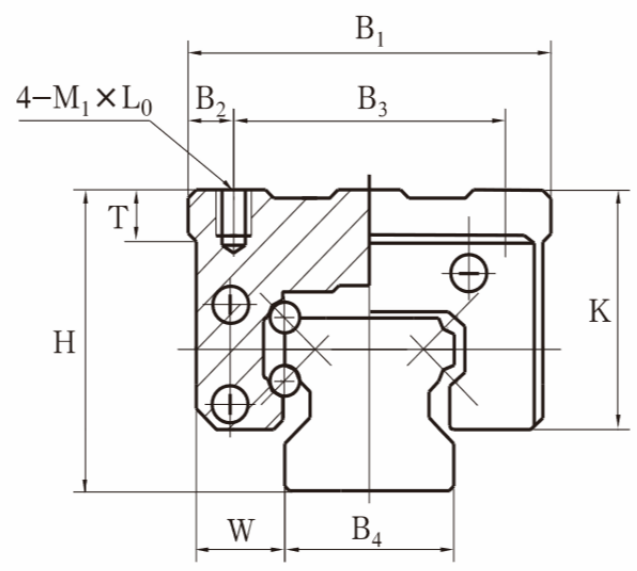

Figure 3. Structure of linear guide pairs.

Figure 4 is shown the general structure of linear guide pair. It consists of ball slide, end cap, side seal (end seal), grease fitting, return guide, balls and rail.

For finite element analysis is taken the simplify model of linear guide pair, ignore other elements are taken the main components: balls, guide and slider. The whole linear guide is shown in Figure 5.

\section{Boundary conditions}

The second step is input CAD model into ANSYS Workbench (Figure 6). Proper element, mesh density, constraint condition, loading steps, point contact links and material property are set up for the model for analysis.

The material is a structural steel. Material properties are for structural steel such as, elastic modulus $\mathrm{E}=206 \mathrm{GPA}$, density $\rho=7800 \mathrm{~kg} / \mathrm{m}^{3}$ and, a Poisson's ratio is 0.3 . Contact with friction is assigned in the joints. The friction coefficient is $\mathrm{F}=0.1$. The mesh generation is a Multizone. In Multizone zones should be mesh-conformal, and all the mesh should be high quality. The rail and slider set grid $2 \mathrm{~mm}$, the arc contact surface and the surface of the ball set the grid size is $0.5 \mathrm{~mm}$. The arc zone meshed less than other zones to see correctly the deformation in zones. The resulting mode contained 120894 elements. The meshing model of linear guide is shown in Figure 7.

The boundary conditions for three linear guides are identical (Figure 8). The load for FEA model is calculated as follows: the maximum load for each linear guide is divided into 32 balls in one circle of row. The number of balls in one raw is calculated such as: the length of slider is divided into ball diameter. In one row there are 16 balls, there are 2 rows in upper row, so the number of balls in upper row are 32 .

For Chinese company: $1-563 \mathrm{~N}$.

For Chinese company: 2-1156 N.

For abroad company: $719 \mathrm{~N}$.

The load is chosen $563 \mathrm{~N}$ as average load for three linear guide pairs, so as further linear guide pairs will compare with each other. The downward load is applied on slider. The contact between ball and groove is: the ball is contact, and groove and the point in slider is a target. The bottom of the guide is chosen as a fixed support. 




Figure 4. Structure of linear guide.



Figure 5. 3D Model of whole linear guide pair.



Figure 6. 3D model of linear guide pair. 

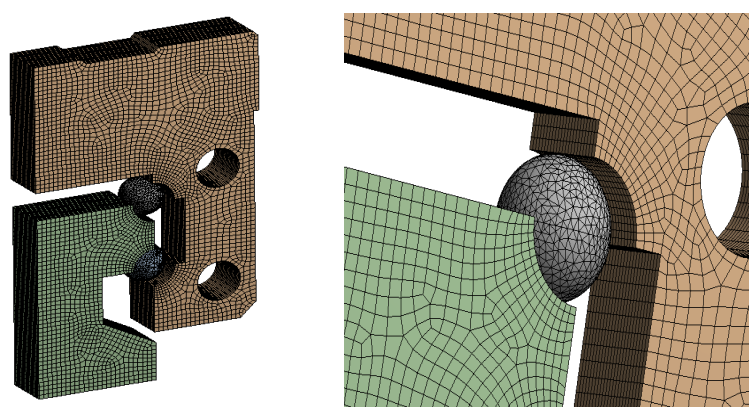

Figure 7. Meshing of model.

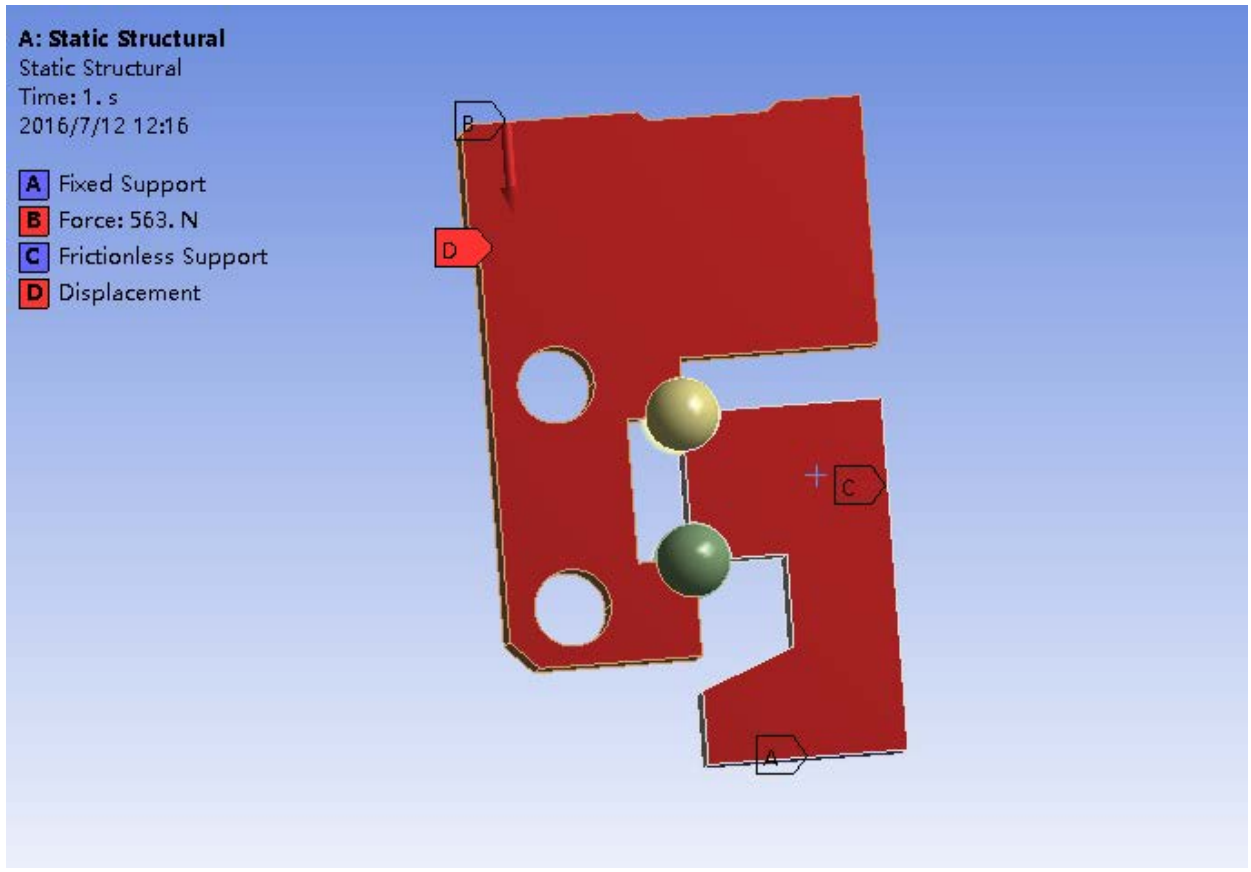

Figure 8. Boundary condition.

Post-process performed: After solving process for FE model was finished, the graphic results of deformation and modal animation of guide pairs were performed by ANSYS Workbench. The measurement results of deformation can compare with the displacement of the node at the central of block.

\subsection{The Finite Element Analysis Results}

Three linear guides with different geometric parameters under one load were investigated. Further compare the results with experiment the load was applied on slider and, got results of simulation: total deformation.

Figure 9 is the results of linear guide pair of Chinese company-1. The results such as: the maximum deformation is shown in the bottom of slider and the minimum deformation is shown in the guide. The maximum total stress is shown in the upper ball of linear guide and the minimum stress is shown in the guide. The total maximum strain is also shown in the upper ball and the minimum strain in the guide. The results of 


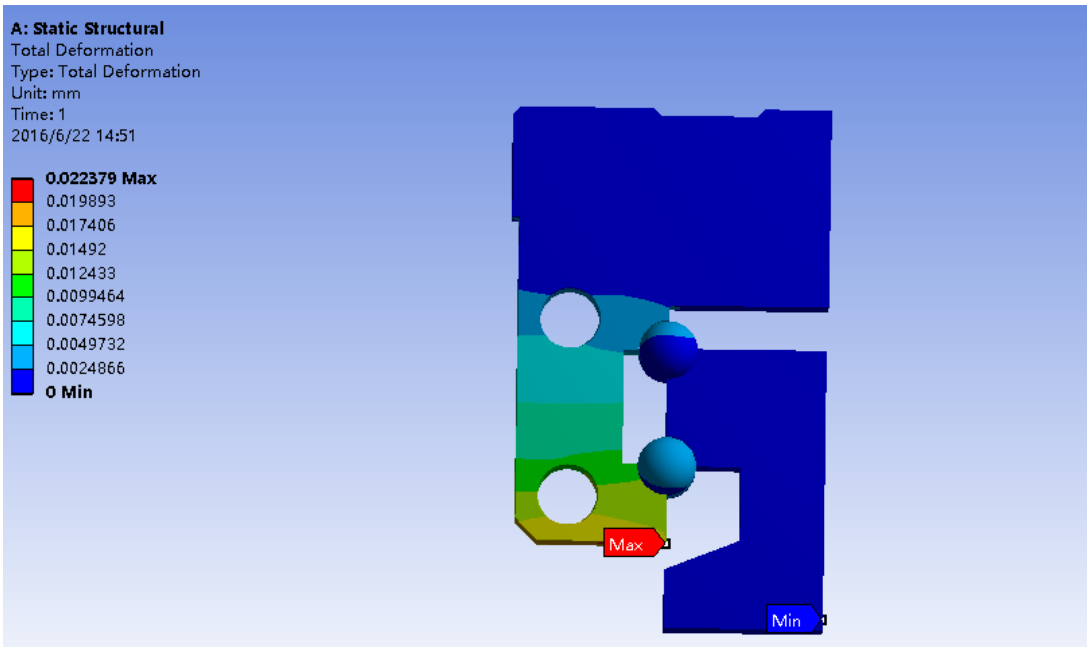

Total deformation



Equivalent of stress

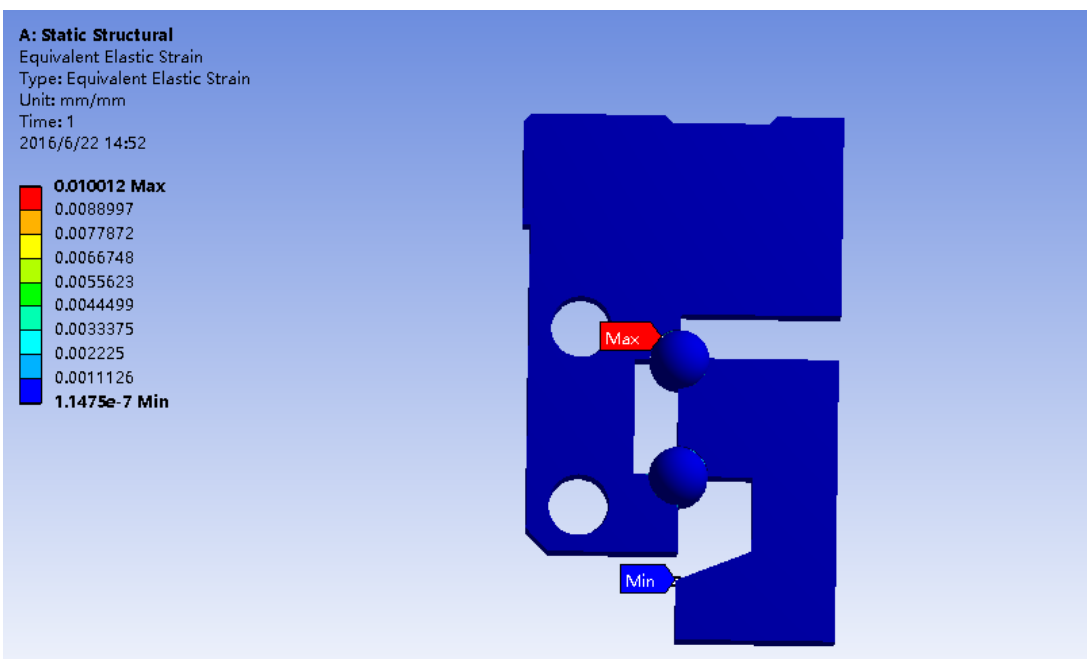

Equivalent of strain

Figure 9. FEA simulation in ANSYS. 
other two linear guide pairs are similar, so no need show the other results. The results of the simulation are shown in Table 2.

Figure 10 shows the total deformation on balls is in the contact arc of slider. Contact between the grooves and ball was saved. In the down row ball was not big deformation. The deformation on guide was in the arc zone of joint place with upper ball. In the down joint arc was not big deformation. The deformation is on slider brightly shown in the down of slider.

In Table 4 is shown the results of FEA simulation under the load. The results are showed almost same results. The abroad company is showed the biggest deformation. According to analysis result of FEA, stiffness value is as follows:

Stiffness of Chinese company- $1: \mathrm{k}=25.157 \mathrm{~N} / \mu \mathrm{m}$.

Stiffness of Chinese company-2: $\mathrm{k}=25.313 \mathrm{~N} / \mu \mathrm{m}$.

Stiffness of abroad company: $\mathrm{k}=22.947 \mathrm{~N} / \mu \mathrm{m}$.

The stiffness of abroad company is $22.947 \mathrm{~N} / \mu \mathrm{m}$ was the minimum. The stiffness of Chinese company- 2 is $25.313 \mathrm{~N} / \mu \mathrm{m}$ was the maximum value. The maximum load for every company is different. The $563 \mathrm{~N}$ is the maximum load for one ball of Chinese company-1. The maximum load for one ball for Chinese company-2 is $1203 \mathrm{~N}$ and for abroad company is $750 \mathrm{~N}$. The FEA verified that the theory on linear guide is applicable, also illustrated the finite element model's contact modelling is correct and feasible.

\section{Experimental Setup}

\subsection{Introduction of Stiffness Measurement Test-Bed}

The amplitude properties of linear guides were measured in stiffness measurement testbed shown in Figure 11. Carrying the capacity is high, so the test-bed has a load stability and high accuracy. The equipment can achieve maximum $600 \mathrm{KN}$ load force and measure the 65 and below series of guideways. Test-bed equipped with $600 \mathrm{KN}$ and following series of guideways. It is for measuring static stiffness. Large-scale force sensor is for measuring static load. The test-bed consists of: double fitting, cylindrical force, slider fixture, motion detector, 4 sensor jigs and rail clamps.

\subsection{The Results of Experiment}

The value of maximum load is taken from every company's handbook. The maximum load for abroad country-24,000 N, Chinese company-1-18,000 N and, Chinese company-2-38,500 N.

Table 2. The results of FEA simulation of same load for one ball

\begin{tabular}{ccc}
\hline & Load & Deformation \\
\hline Chinese company-1 & $563 \mathrm{~N}$ & $22.379 \mu / \mathrm{m}$ \\
Chinese company-2 & $563 \mathrm{~N}$ & $22.241 \mu / \mathrm{m}$ \\
Abroad company & $563 \mathrm{~N}$ & $24.535 \mu / \mathrm{m}$ \\
\hline
\end{tabular}




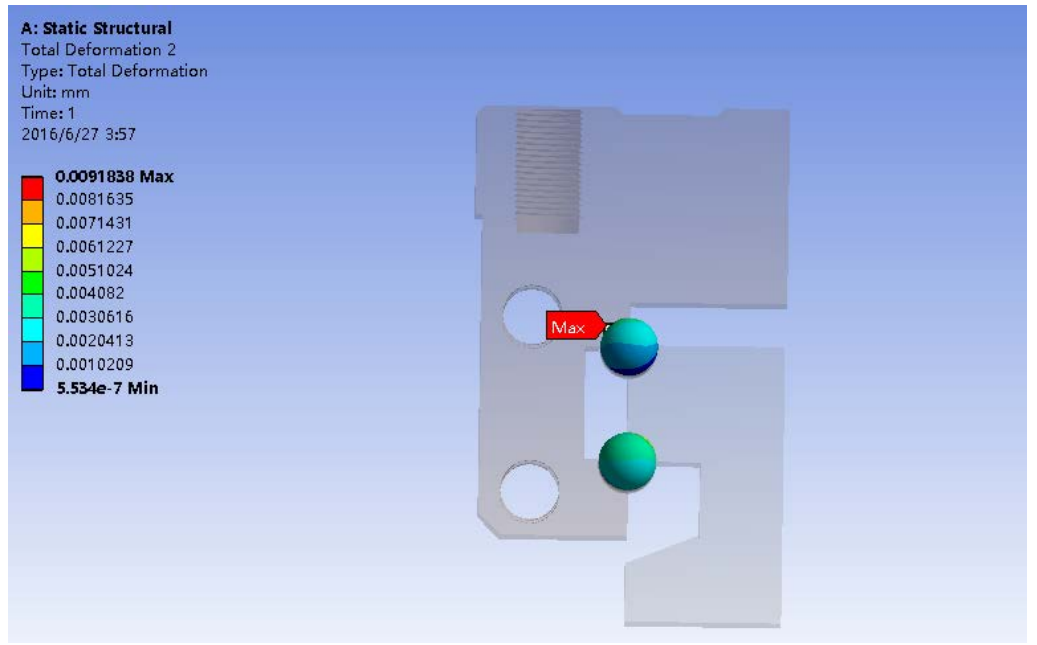

Total deformation of balls

A: Static Structural
Total Deformation 4
Type: Total Deformation
Unit: $\mathrm{mm}$
Time: 1
$2016 / 6 / 273: 59$
$\begin{aligned} & 0.00065117 \mathrm{Max} \\ & 0.00057882 \\ & 0.00050647 \\ & 0.00043411 \\ & 0.00036176 \\ & 0.00028941 \\ & 0.00021706 \\ & 0.0001447 \\ & 7.2352 \mathrm{e}-5 \\ & 0 \mathrm{Min}\end{aligned}$

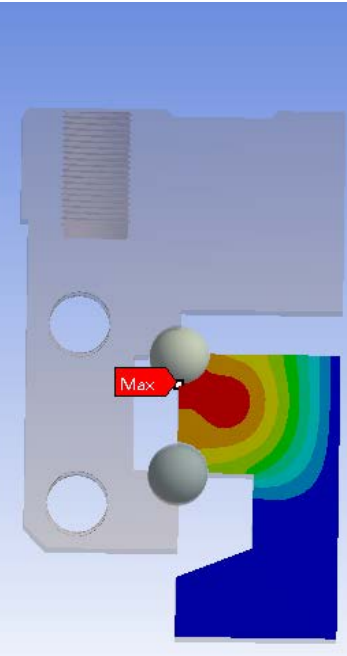

Total deformation of guide

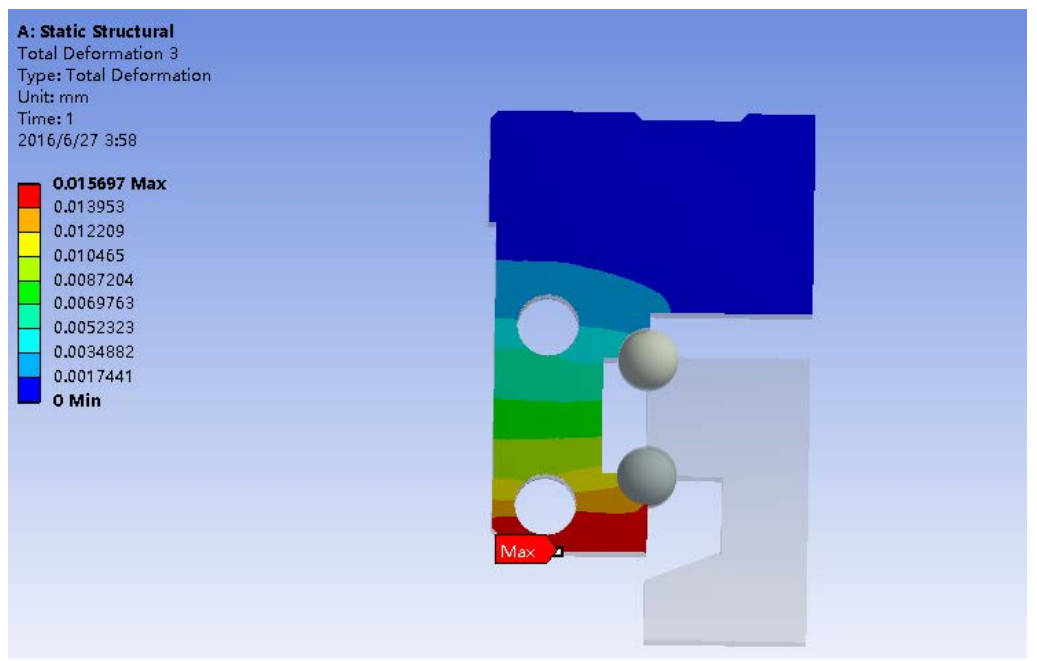

Total deformation of slider

Figure 10. Total deformation of balls, guide and slider. 


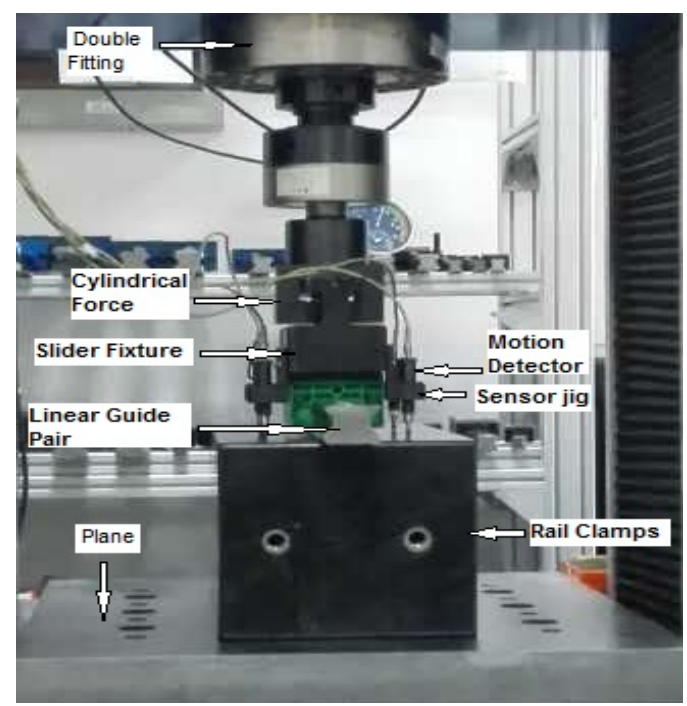

Figure 11. The stiffness measurement test-bed.

In Figure 12 is shown three companies stiffness results load and preload lines. The results are taken of $18000 \mathrm{~N}$ further comparison with FEA results. The load of experiment is 32 times bigger than the load applied in FEA. According to analysis result of deflection, stiffness value can be expressed as follows:

$$
k=\frac{F}{\delta}
$$

where, $F$-is the force applied on the body, $\delta$-is the displacement produced by the force along the same degree of freedom.

Stiffness of Chinese company- $1 \mathrm{k}=789.474 \mathrm{~N} / \mu \mathrm{m}$.

Stiffness of Chinese company- $2 \mathrm{k}=857.143 \mathrm{~N} / \mu \mathrm{m}$.

Stiffness of abroad company $\mathrm{k}=705.882 \mathrm{~N} / \mu \mathrm{m}$.

Table 3 shows the deformation of three linear guides under the one load. The maximum load for each linear guide is different. The deformation under one load was chosen for additional comparing with FEA results.

\section{Comparison and Discussion of FEA and Experimental Results}

In additional, the stiffness obtained from finite element simulation and experiment need to compare. The measured linear guides by experimentally have 16 balls on each row of groove, it means on the upper rows 32 balls. Therefore, the defined stiffness should be 32 times in FEA model. Figure 13 shows differences stiffness between experiment and finite element analysis.

Figure 13 is showed the comparison of experiment and FEA results. The model is used in FEA consists of slider, guide and balls. And, the full model of linear guide pairs has many components which effect to analysis. Some of components are made from plastic which also has influence for analysis. According to this details of linear guide pairs model, the FEA analysis and experiment analysis has differences.

Table 4 shows the deformation of linear guide pairs with different structure. The 
A. Shaukharova et al.



Chinese company-1

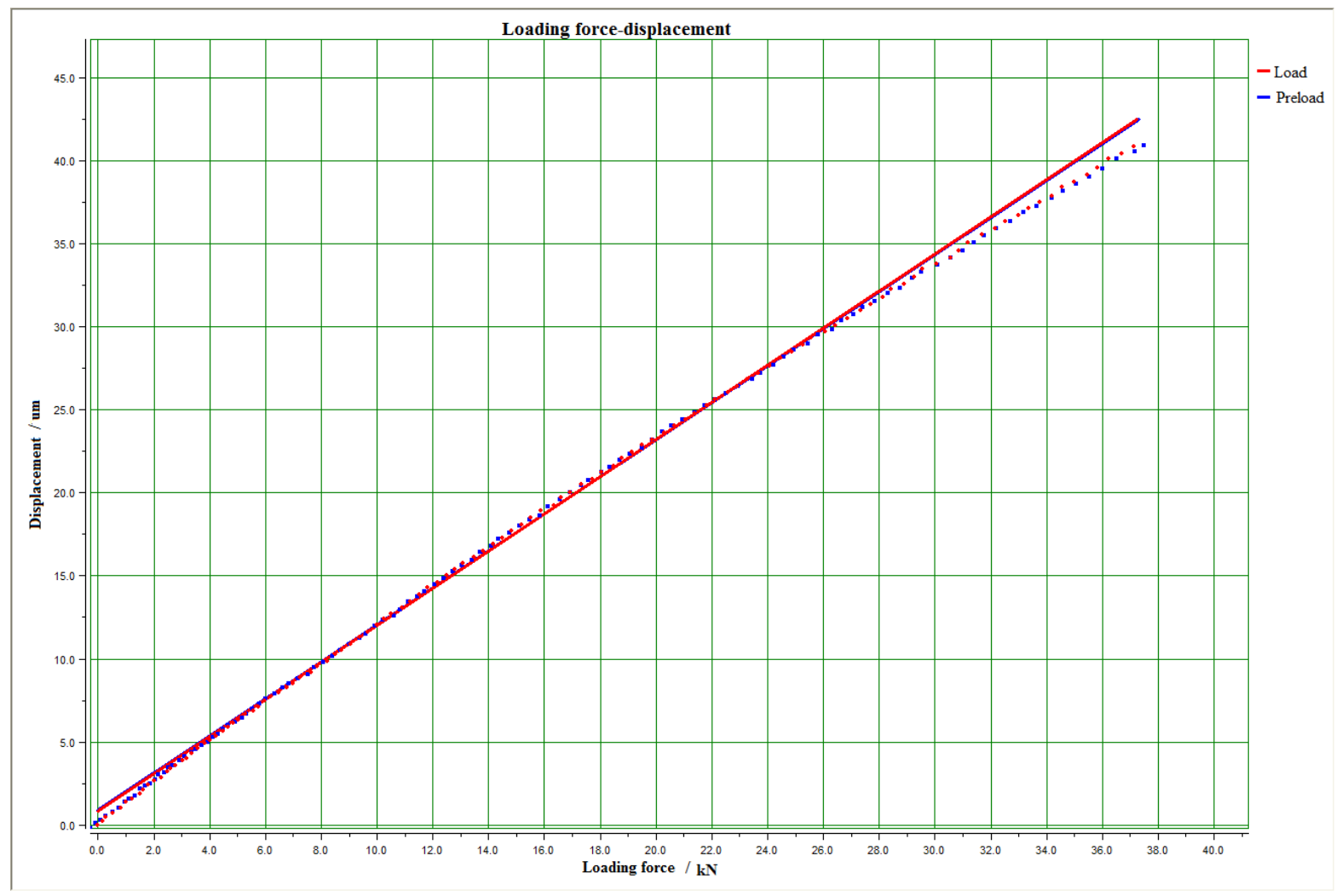

Chinese company-2 




Figure 12. The preload and load curves of stiffness. The blue line shows the preload and the red line shows load.

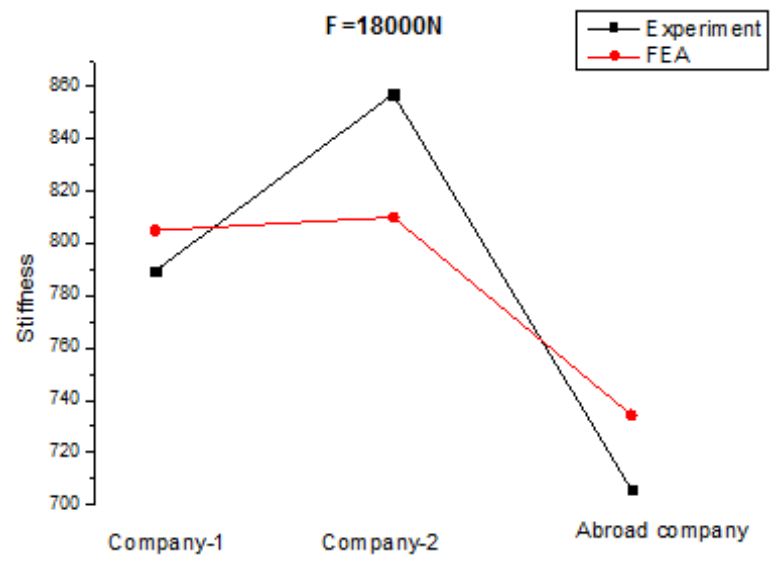

Figure 13. Stiffness results by FEA and experiment.

Table 3. The deformation of linear guide pairs experimentally.

\begin{tabular}{ccc}
\hline & Load & Deformation \\
\hline Chinese company-1 & $18,000 \mathrm{~N}$ & $22.8 \mu \mathrm{m}$ \\
Chinese company-2 & $18,000 \mathrm{~N}$ & $21.2 \mu \mathrm{m}$ \\
Abroad company & $18,000 \mathrm{~N}$ & $25.5 \mu \mathrm{m}$
\end{tabular}


Table 4. The comparison of deformation of linear guide pairs.

\begin{tabular}{ccc}
\hline & FEA & experiment \\
\hline Chinese company-1 & $22.379 \mu \mathrm{m}$ & $22.8 \mu \mathrm{m}$ \\
Chinese company-2 & $22.241 \mu \mathrm{m}$ & $21.2 \mu \mathrm{m}$ \\
Abroad company & $23.535 \mu \mathrm{m}$ & $25.5 \mu \mathrm{m}$ \\
\hline
\end{tabular}

load is chosen $18,000 \mathrm{~N}$ for every linear guide pairs further to compare with each other. The load for FEA analysis is chosen $563 \mathrm{~N}$ for one ball of linear guide pair. The result of experiment and FEA shows almost the same results. According to the stiffness measurement, the Chinese company-2 linear guide pair has high stiffness. The maximum load for this linear guide pair is $38,500 \mathrm{~N}$. For Chinese company-1 $\mathrm{F}=18,000 \mathrm{~N}$ is the maximum load. And, the maximum load for the abroad company is $24,000 \mathrm{~N}$. And the length of slider of Chinese company- 2 is higher than the other two companies linear guide pairs. The structure of Chinese company- 2 is suitable for the service under the big load. According to the FEA and experiment analysis, the Chinese company's structure obtained like suitable one for creating the linear guide pairs.

\section{Conclusions}

In this paper, we obtained effect of different structures of linear guides on properties. Three linear guides examined: Chinese company-1, Chinese company- 2 and abroad company.

The stiffness was measured by experimentally and also for comparison the finite element simulation is done in ANSYS Workbench for three linear guides. The study has following conclusion:

1) The finite element analysis shows good results in the prediction of the dynamic behaviours of the linear guides comparing the experimental results.

2) FEA results show the maximum deformation was in the down of slider and the minimum deformation was in guide for all linear guides.

3) FEA results show the maximum stress and strain was in the upper ball and the minimum stress and strain in the down ball for all linear guides. Contact between ball and groove is not changed.

4) The analysis is showed that the different structure of linear guide pairs effect to the stiffness property of linear guide pair.

5) According to the analysis, the linear guide pair with good structure is obtained.

\section{References}

[1] Thomson. Linear Motion. Optimized. Selecting and Applying Rolling Element. Linear Bearings and guides. www.thomsonlinear.com

[2] Nuij, P. and Steinbuch, M. (2004) Two Measurement Techniques to Determine Higher Order Sinusoidal Input Describing Functions. Proceedings of ISMA 2004, Leuven, 2145-2154.

[3] Yi, Y.-S., Kim, Y.Y., Choi, J.S., Yoo, J., Lee, D.J., Lee, S.W. and Lee, S.J. (2008) Dynamic Analysis of a Linear Motion Guide Having Rolling Elements for Precision Positioning De- 
vices. Journal of Mechanical Science and Technology, 22, 50-60.

http://dx.doi.org/10.1007/s12206-007-1006-9

[4] Lai, Y.L. and Hung, J.P. (2012) The Influence of Linear Guide Arrangement on the Dynamic Characteristics of a Gantry Type Milling Machine. Journal of the Chinese Society of Mechanical Engineers, 35, 113-122.

[5] Young-Sub, Y., Kim, Y.Y., Choi, J.S., et al. (2008) Dynamic Analysis of a Linear Motion Guide Having Rolling Elements for Precision Positioning Devices. Journal of Mechanical Science and Technology, 22, 50-60. http://dx.doi.org/10.1007/s12206-007-1006-9

[6] Hung, J.P. (2009) Load Effects on the Vibration Characteristics of a Stage with Rolling Guides. Journal of Mechanical Science and Technology, 23, 89-99.

http://dx.doi.org/10.1007/s12206-008-0925-4

[7] Harsha, S.P., Sandeep, K. and Prakash, R.E. (2003) Effects of Preload and Number of Balls on Nonlinear Dynamic Behaviours of Ball Bearings System. International Journal of Nonlinear Science and Numerical Simulation, 4, 265-278.

[8] Lynagh, N., Rahnejat, H., Ebrahimi, M. and Aini, R. (2000) Bearing Induced Vibration in Precision High Speed Routing Spindles. International Journal of Machine Tools and Manufacture, 40, 561-577. http://dx.doi.org/10.1016/S0890-6955(99)00076-0

[9] Hung, J.P., Wu, J.S.S. and Chiu, J.Y. (2004) Impact Failure Analysis of Re-Circulating Mechanism in Ball. Engineering Failure Analysis, 4, 561-573.

http://dx.doi.org/10.1016/j.engfailanal.2004.01.002

[10] Dadalau, A., Groh, K., Reuß, M. and Verl, A. (2012) Modelling Linear Guide Systems with CoFEM: Equivalent Models for Rolling Contact. Production Engineering, 61, 39-46. http://dx.doi.org/10.1007/s11740-011-0349-3

[11] Wu, J.S.-S., Chang, J.-C., Tsai, G.-A., Lin, C.-Y. and Ou, F.-M. (2012) The Effect of Bending Loads on the Dynamic Behaviours of a Rolling Guide. Journal of Mechanical Science and Technology, 26, 671-680. http://dx.doi.org/10.1007/s12206-011-1228-8

[12] Li, L. and Zhang, J. (2011) Parameters Identification and Dynamic Analysis of Linear Rolling Guide. Advanced Materials Research, 199-200, 7-12.

http://dx.doi.org/10.4028/www.scientific.net/AMR.199-200.7

[13] Shaw, D. and Lsu, W. (2011) Study of Stiffness of a Linear Guideway by FEA and Experiment. Tech Science Press. SL, 5, 129-138.

[14] Zatarain, M., Lejardi, E., Egana, F. and Bueno, R. (1998) Modular Synthesis of Machine Tools. CIRP Annals - Manufacturing Technology, 47, 333-336. http://dx.doi.org/10.1016/S0007-8506(07)62845-5

[15] Spath, D., Neithardt, W. and Bangert, C. (2002) Optimized Design with Topology and Shape Optimization. Proceedings of the Institution of Mechanical Engineers B: Journal of Engineering Manufacture, 216, 1187-1191. http://dx.doi.org/10.1243/095440502760272458

[16] Reinhart, G. and Weissenberger, M. (1999) Multibody Simulation of Machine Tools as Mechatronic Systems for Optimization of Motion Dynamics in the Design Process. Proceedings of the IEEE/ASME International Conference on Advanced Intelligent Mechatronics (AIM'99), Atlanta, 605-610. http://dx.doi.org/10.1109/aim.1999.803237

[17] Witt, S., Queins, M. and Brecher, C. (2004) Coupled Simulation of Structural Dynamics and Control Loop with MSC.ADAMS for the Development of High-Dynamic Machine Tools. Proceedings of the Virtual Product Development Conference, Munchen.

[18] Law, M., Altintas, Y. and Phani, A.S. (2013) Rapid Evaluation and Optimization of Machine Tools with Position-Dependent Stability. International Journal of Machine Tools and Manufacture, 68, 81-90. http://dx.doi.org/10.1016/j.ijmachtools.2013.02.003 
Submit or recommend next manuscript to SCIRP and we will provide best service for you:

Accepting pre-submission inquiries through Email, Facebook, LinkedIn, Twitter, etc. A wide selection of journals (inclusive of 9 subjects, more than 200 journals)

Providing 24-hour high-quality service

User-friendly online submission system

Fair and swift peer-review system

Efficient typesetting and proofreading procedure

Display of the result of downloads and visits, as well as the number of cited articles

Maximum dissemination of your research work

Submit your manuscript at: http://papersubmission.scirp.org/

Orcontactwjet@scirp.org 